Engineering \& Technology | Fabian Fischer

\title{
Solving phosphate scarcity with wastewater refining
}

Satisfying the intense

consumption habits of modern society requires an unsustainable exploitation of natural resources waste. The linear consumption process of extraction, use,

and disposal is causing drastic environmental imbalances. One way of tackling this challenge is to adopt a circular economy, in which waste is transformed into renewable resources. Professor Fabian Fischer and his team at the University of Applied have developed a three-step wastewater refining process th recovers phosphate fertiliser and other materials from sewage sludge with great efficiency, providing an excellent example
of a circular economy approach.

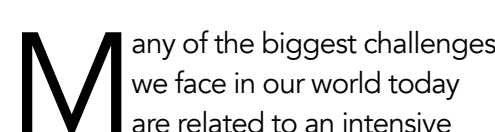
Wre related to an intensive our consurtion hats lead to an accelerated use of resoud thes that not allow sufficient time for them to be replenished before being extracted again. This unsustainable cycle results in environmental imbalances which are ultimately responsible for the drastic changes we are witnessing in the natur world, through phenomena such as climate change, plastic pollution and biodiversity collapse.

We urgently need to develop and implement solutions to halt the intensive extraction of natural resources and the irresponsible disposal of the waste produced in the process. The concept of a circul in tonomy has emerged from this need to reduce our dependence on it aims to redefine growth, moving socity away from consumption of finite noturat

resources and towards products and processes which are designed to yield reusable 'waste'.

\section{WASTE IN, RICHES OUT}

Achieving a truly sustainable world of renewable resources will require the development of smart solutions that can ddress multiple challenges at once. Any given sustainability solution should be able to use waste materials to generate resources requiring only minimal amounts of renewable energy to do so. In addition, any materials or by-products generated in the process also need to be non-toxic, being safe for either re-use or sustainable disposal.

Professor Fabian Fischer, and his team at the University of Applied Sciences of Western Switzerland, has developed an integrated process that turns different types of waste into different types Fischer's-use resources. Professor of wastewater refining which uses the microbial power contained within municipal wastewater to generate a chemical base (a high pH species), cleans wastewater and extracts fertiliser and other valuables from wet sewage sludge.

\section{HARNESSING MICROBIAL POWER} The process is divided into three main stages. The first part of the process takes place in a microbial electrolysis cell, which consists of two chambers: one of them is an anode chamber (ie. electron extracting) and the other is a cathode chamber (ie. electron donating), akin to a battery. The two chambers are separate by an ion exchange membrane, and made of reticulated vitreous carbon, a material whose appearance resembles a carbon sponge. This reticulated vitreous char as high suface area and low reactivity: its quality and easy handling also offer important benefits for construction.

Municipal wastewater, full of nutrients and contaminants, is fed into the anodic chamber of the microbial electrolysis cell and is then in contact with the electrodes inside this chamber. When a small voltage - generated from renewable energy sources - is applied to these electrodes, they extract electrons from the wastewater mixture, leaving behind charged particles of the nutrients and pollutants present in the wastewater. The extracted electrons travel to the electrode in the adjacent cathodic chamber, which is filled with pure in the cathodic chamber reacts with the water to generate a chemical base, namely hydroxide ion $\left(\mathrm{OH}^{-}\right)$, and hydrogen. This first step thus uses the microbial power contained within the wastewater to purify the wastewater and generate the chemica base $\mathrm{OH}^{\text {, and extracts ammonia, an }}$ important fertiliser compound, with only small voltage being applied.

RECYCLING SEWAGE SLUDGE Apart from purifying wastewater, the chemical base generated in Stage I of Professor Fischer's three-step process can also be used to extract important materials from wet sewage sludge, which constitutes Stage ll of the process. Sewage sludge phosphate $\mathrm{Fe}_{3}$ which reacts with the chemical bas

to precipitate solid $\mathrm{Fe}(\mathrm{OH})_{3}$, leaving used in fertiliser. This process of releasing

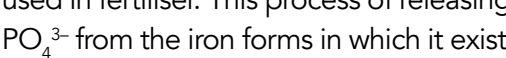
in sewage sludge is called phosphate A cir
gro
ansu
aving

A circular economy aims to redefine growth, moving society away from

significant market value and have the chemical base removes toxic metals and pecipitates other components, leading to other reusable solid materials from wastewater.

Stage III of the process consists of the crystallisation of struvite (phosphate mineral fertiliser) from the remobilisation mixtures obtained in Stage li. Apart fiom developed prototype versions of the scaled it up and placed three full-size (168 litre) reactors in three different, fully functioning wastewater treatment plants In Swizzerland. Even in these real-life esearchers were able to recover more than $90 \%$ of the phosphate present
in sewage sludge in sewage sludge and generate struvite
fertilisers that fulfilled legal requirements remobilisation. In a similar fashion, the as ammonia, magnesium, calcium and potassium. In addition, the phosphatefree sludge that is left behind can be used as a biofuel. All of the extracted materials, and sewage sludge as an input, have a researchers also carried out significant extracts and fertilisers resulting from the metal content, microbial contaminants with respect to toxic metal content. The esting on the sewage sludge, liquid process in order to assess their heavy

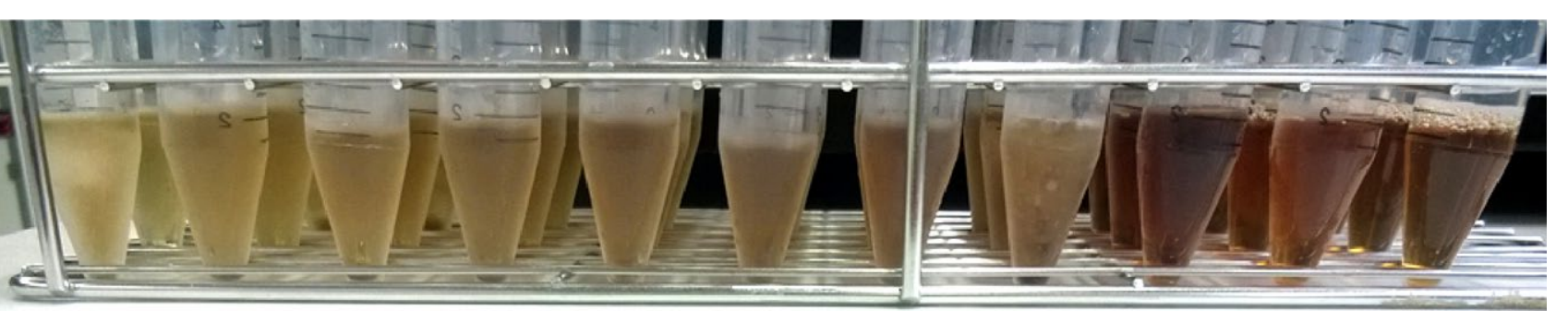

Left: Start of phosphate remobilisation. Right: Dark brown solutions with high phosphate concentrations ready for fertiliser production. 


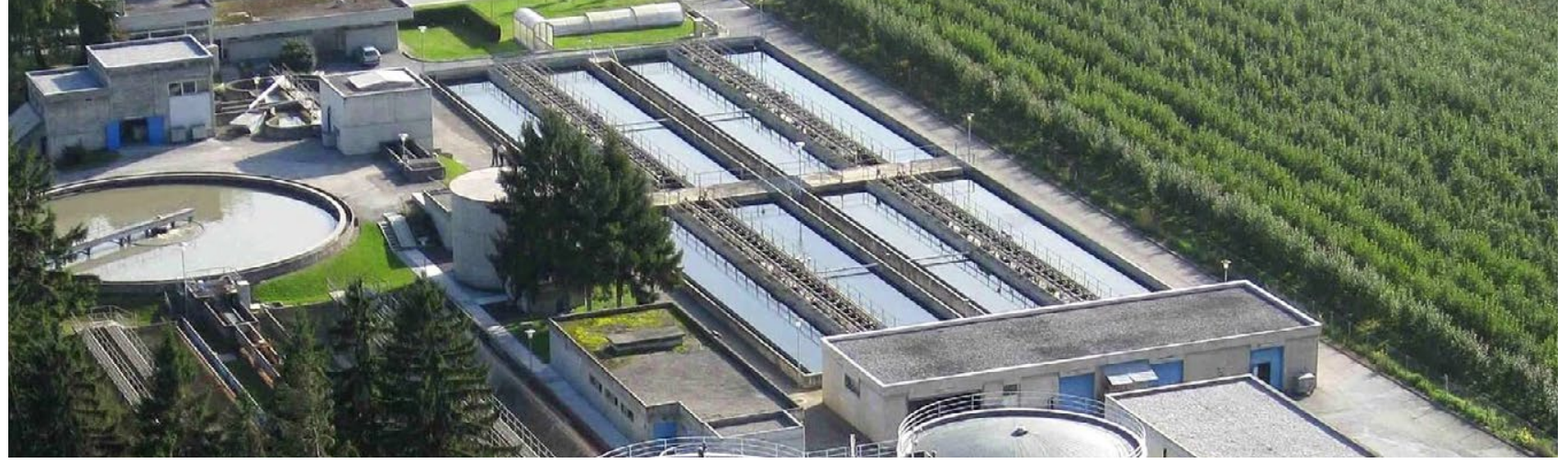

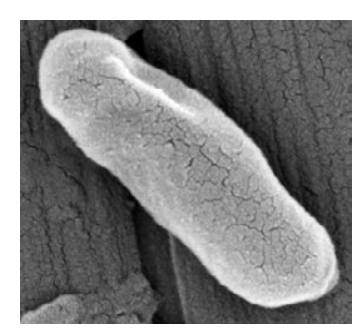

Microbial power from
bioelectric-reactor

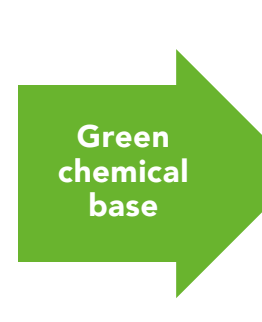

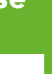

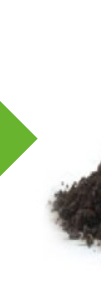

Digested seweges sudde
contanining wase pep hosphorous

Top: State of the art wastewater treatment plant. Bottom: New phosphate recovery process, not yet implemented.

and other micropollutants, and found all samples to be within the required limits for further use.

To further evaluate the viability of widespread deployment of their technology, the researchers also carried out an economic analysis of the system. Taking into account the energy required to run the system and the marketable products generated, including the phosphate fertilisers and phosphate-free biofuel, the team found that a profit of 0.11 Swiss francs could be obtained per kilogram of struvite generated. With the reuse of other marketable by-products, such as magnesium and calcium, the already positive economic viability of this technology could be further improved. This type of integrated technology, which uses waste to generate renewable challenges at once, is a prime example of what a circul ceconomy can example of

\section{PHOSPHATE FERTILISERS AND}

\section{FOOD PRODUCTION}

The novel wastewater refining system developed by Professor Fischer and his team offers an important alternative to such as agriculture. Despite being a very important sector of human activity, agriculture can also have a severe, sometimes negative, impact on the environment.

Agriculture depends on one of the most precious natural resources on Earth -

water - which, given its crucial role in
sustaining life on Earth, requires careful system with low energy demands, in management. While normal weather events can lead to temporary water the severity and length of drought events, therefore emphasising the need for efficient water use. In this context, Professor Fischer's system provides an important alternative for water extraction, as it not only allows for wastewater reuse

security, as agriculture depends on vields to satisfy de food in sufficient phosphate needed for fertilisers is mine from phosphate rock, but this finite natural resource is expected to deplete in 50 to 80 years, with peak production being reached as early as 2030. A reduced availability of phosphate for use

Even in real-life conditions, the researchers were able to recover over $90 \%$ of the phosphate present in sewage sludge.

but it does so through a sustainable stark contrast with current
management techniques. The generation of phosphate fertilisers by Professor Fischer's system is also

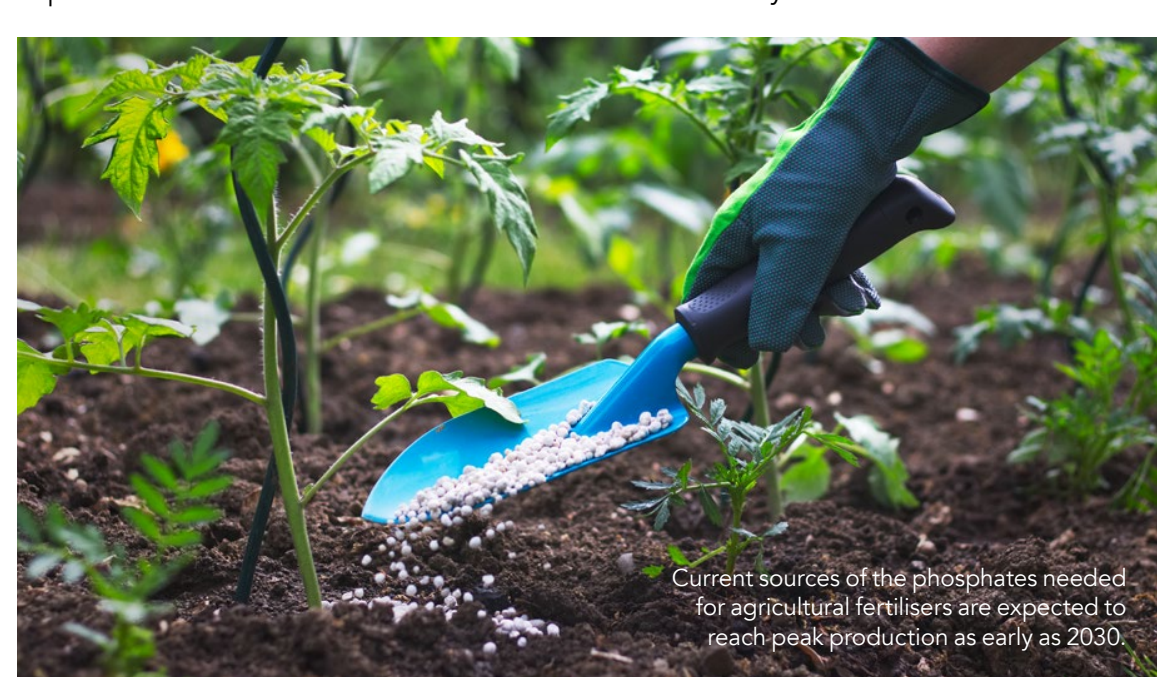

in fertilisers would raise the cost of food and ultimately lead to food shortages, threatening food security. As such, Professor Fischer's circularity approach to efficient wastewater reuse, creating also an is an important contribution towards mor

\section{Behind the Research}

\section{Professor Fabian Fischer}

E: fabian.fischer@hevs.ch T: +41 (0)58 6068658 muww.linkedin.com/in/fabian-fischer-2560a2203
W: scholar.google.ch/citations?user=gxOdEfEAAAAJ\&hl=de

Research Objectives

Professor Fischer's work focuses on renewable energy, specialising in bioelectric systems, biotransformation and chemical biotechnology.

\section{Detail}

Address

Life Technologies Institute, HESSO Switzerland

Bio

After obtaining a PhD in Chemistry at the University of Bern, Fabian Fischer Berkeley, and the Marie Curie University

References

Blatter, M., et al. (2020). Phosphorus, chemical base and oherrenewables from wastewater electrolysis cells and other unit operations. Chemica
Engineering Journal, 390, 124502. doi.org/10.1016/1. cej. 2020.124502

Ellen MacArthur Foundation (2017). What is a circular regenerative by design. [online] ellenmacarthurfoundation. org. Available at. www.ellenmacarthurfoundation.org/circulareconomy/concept [Accessed 04 July 2021].

Fischer, F., et al. (2015). Microbial electrolysis cell accelerates phosphate remobilisation from iron phosphate contained in sewage sludge. Environmental Science: Processes and

Impacts, 17, 90-97. doi.org/10.1039/C4EMO0536H Cordell, D., et al. (2009). The story of phosphorus: Global food 19(2), 292-305. doi.org/10.1016/i.gloenvucha.2008.10.009

\section{Landor (fenaco), Satom and Altis: all in Switzerland. \\ Collaborators Christele Bastian, Maxime Blatter, Christian P. Cachelin, Christos Comninellis, Clément Furrer, Manuel Happe, Eric Mabillard, Géraldine Pouge Vermeille}

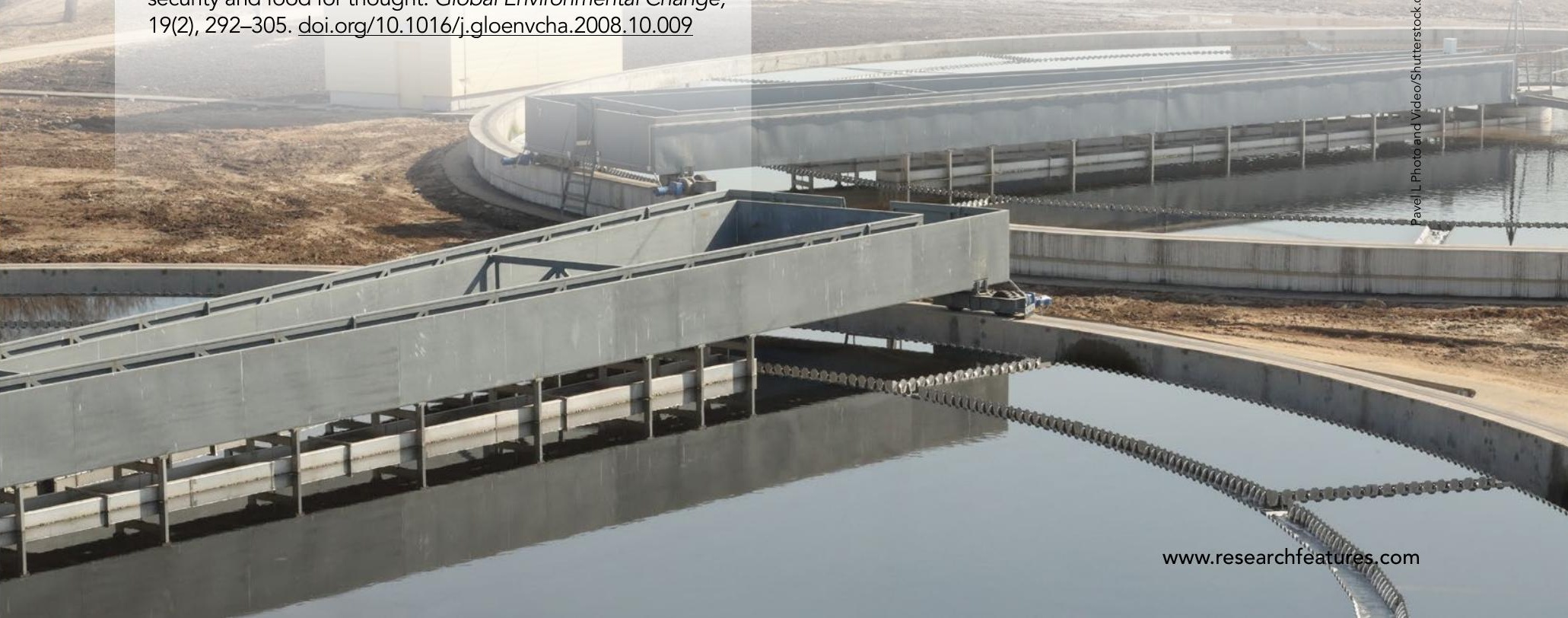

\section{Personal Response}

How close is this technology from deployment and widespread use in wastewater treatment plants?

III The technology functions well on pilot scale as phosphate is recoverable above $90 \%$ and this in a real-world setting. Ammonia, a second fertiliser compound, is equally fertiliser fulfilling legal requirements for farphosphatephosphate fertilisers are equally producible with the system. did obtained solid biofuel is useful to produce $\mathrm{CO}^{-}$-reduced cement and leads to traceless sewage sludge
disposal. And finally, wastewater is purified in the so-called 'microbial fuel cell' process for less cost in comparison to
state-of-the-art wastewater treatment. 